\title{
BREECH PRESENTATION: RCT of IV REMIFENTANIL FOR ECV ATTEMPT
}

Authors: Dr. A. Macarthur MDi, Dr. S. Gagnon MD', Dr. J. Kingdom MbChB ${ }^{\mathrm{ii}}$, Dr. L. Tureanu MD ${ }^{\mathrm{i}}$, Dr. J. Dasan MbChBi, Kristi Downey MSc ${ }^{\mathrm{i}}$

Affiliation: Department of Anesthesia ${ }^{i} \&$ Obstetrics $^{\mathrm{ii}}$, Mount Sinai Hospital, 600 University Avenue, Toronto, Ontario, Canada M5G 1X5

Introduction: Breech presentation is now an indication for cesarean delivery, however external cephalic version (ECV) maneuvers are proven therapy to reduce this event. ${ }^{1}$ Meta-analysis review of regional anesthesia for has demonstrated a benefit of anesthesia for ECV success and maternal satisfaction. ${ }^{2}$ However, regional anesthesia has complications and potentially IV analgesia might provide similar benefits. The objective of this study was to compare the incidence of success ECV between women receiving remifentanil intravenous (IV) analgesia and women receiving placebo.

Methods: Following local institutional REB approval, this double-blind, placebo-controlled RCT recruited women with documented breech presentations $>35 / 52$ scheduled for elective ECV attempts. Women were randomized to IV remifentanil infusions $(25 \mathrm{mcg} / \mathrm{ml})$ starting at $0.1 \mathrm{mcg} / \mathrm{kg} / \mathrm{min}$ or IV saline at the same settings prior to the ECV attempt. An algorithm was established for changing the infusion and using IV boluses ( $25 \mathrm{mcg}$ remifentanil or placebo). The primary outcome was the proportion of women with successful ECV maneuvers, defined by ultrasound. Secondary outcomes included maternal pain scores, obstetrician and maternal satisfaction scores, side effect and complication rates. Demographic information was collected to assess randomization.

Results: The study was conducted between May 2003 - December 2004 and was halted prematurely. Unexpected difficulty in recruitment was encountered because of limited operating room time available for this procedure. During this period, only 122 patients were eligible for study recruitment, 11 women were randomized and 2 withdrew prior to ECV.

\begin{tabular}{|l|c|c|c|}
\multicolumn{1}{c}{ Outcome } & $\begin{array}{c}\text { Remifentanil group } \\
(\mathbf{N = 4 )}\end{array}$ & $\begin{array}{c}\text { Placebo group } \\
(\mathbf{N}=\mathbf{5})\end{array}$ & p value \\
\hline Successful ECV attempt & $1 / 4$ & $2 / 5$ & 0.59 \\
\hline Cephalic presentation @ delivery & $1 / 3$ & $2 / 5$ & 0.71 \\
\hline Vaginal delivery & $1 / 3$ & $2 / 5$ & 0.71 \\
\hline Maternal VAS pain during ECV & $6.0( \pm 0.77 \mathrm{sd})$ & $3.7( \pm 2.6 \mathrm{sd})$ & 0.10 \\
\hline Maternal satisfaction & $2 / 4$ comfortable & $0 / 5$ comfortable & 0.17 \\
\hline Obstetric satisfaction & $3 / 4$ agreeable & $3 / 5$ agreeable & 0.83 \\
\hline
\end{tabular}

Discussion: The dose of remifentanil used did not cause cardiorespiratory complications or loss of maternal recall. However, remifentanil and other IV sedation methods must be evaluated for effects on ECV outcome, maternal satisfaction, and maternal pain scores.

References:

1. Cochrane DSR 2001; 3:CD000184. 2. AJOG 2004; 191: $1219-24$. 